\title{
Single walled carbon nanotubes (SWCNT) affect cell physiology and cell architecture
}

\author{
Jean-Pierre Kaiser • Peter Wick • Pius Manser • \\ Philipp Spohn · Arie Bruinink
}

Received: 26 June 2007/ Accepted: 2 October 2007/Published online: 8 November 2007

(C) Springer Science+Business Media, LLC 2007

\begin{abstract}
Single walled carbon nanotubes (SWCNT) find their way in various industrial applications. Due to the expected increased production of various carbon nanotubes and nanoparticle containing products, exposure to engineered nanoparticles will also increase dramatically in parallel. In this study the effects of SWCNT raw material and purified SWCNT (SWCNT bundles) on cell behaviour of mesothelioma cells (MSTO-211H) and on epithelial cells (A549) had been investigated. The effect on cell behaviour (cell proliferation, cell activity, cytoskeleton organization, apoptosis and cell adhesion) were dependent on cell type, SWCNT quality (purified or not) and SWCNT concentration.
\end{abstract}

\section{Abbreviations \\ SWCNT Single walled carbon nanotubes \\ MWCNT Multi walled carbon nanotubes \\ CNT Carbon nanotubes}

\section{Introduction}

Multi walled carbon nanotubes (MWCNT) had been discovered in 1991 by Iijima [1]. Iijima synthesised MWCNT by the arc-discharge evaporation technique, which was already known for the synthesis of fullerene. The MWCNT comprised of coaxial tubes of graphite sheets, ranging from 2 to $50 \mathrm{~nm}$ in diameter. Today there were several technologies

J. P. Kaiser $(\bowtie) \cdot$ P. Wick · P. Manser · P. Spohn · A. Bruinink Materials Biology Interactions Laboratory, Materials Science and Technology (Empa), Lerchenfeldstrasse 5,

St. Gallen CH 9014, Switzerland

e mail: jean pierre.kaiser@empa.ch for the production of carbon nanotubes in an industrial scale, such as arc discharge [1], laser ablation [2] and chemical vapour deposition [3]. All three technologies need metals such as iron, nickel, cobalt, yttrium, etc., as catalysts to increase the yield of carbon nanotubes. Metal catalysts were also necessary for the production of single walled carbon nanotubes (SWCNT). The obtained carbon nanotubes, SWCNT as well as MWCNT contain beside the metal catalysts a substantial amount of amorphous as well as soot like carboneous particles.

Many technical applications however, need carbon nanotubes of high purity. The purification of SWCNT is difficult and time consuming since SWCNT and amorphous carbon exhibit similar chemical properties. The conventional purification process is based on an acid/oxidation treatment. As a result of this procedure a reduction in metallic impurities is achieved and the single walled carbon nanotubes partially break-up and the size of the carbon nanotubes agglomerates decrease [4]. It cannot be excluded that the acid treatment causes some functionalization of the carbon nanotubes. Carbon nanotubes find their way in various industrial applications due to their novel physical and chemical properties. The material is currently used in composite materials [5], in electronics [6] and in the medical field [7]. Due to the expected increased production of various carbon nanotubes and nanoparticle containing products in the coming years environmental and public exposure to engineered nanoparticles will also increase in parallel. It is known that nanosized materials may have hazardous effects and can influence cell behaviour [8 10]. If and in how far carbon nanotubes are able to affect health is quite controversially discussed in the literature [11 13 . An assessment is complicated because various factors such as purity, surface chemistry, surface area, aggregation, catalyst and soot like contamination have different and synergistical impact on the 
biological effects [14]. Furthermore, the methodology to disperse and administrate the CNT may affect the outcome. Regarding the in vivo effects of CNT it had been observed, that when guinea pigs had been exposed to different types of MWCNT for 90 days, the particles could produce inflammatory reactions of bronchioles and even in some animals mild fibrosis [15]. Lam and coworkers [16] investigated in an intratracheal instillation study the effect of different SWCNT on mice. The results from all types of tested SWCNT showed lung lesions in a dose dependent manner.

At cellular level, Muller and coworkers [17] reported using macrophages that CNTs are cytotoxic and that the adverse effects of multi walled carbon nanotubes (MWCNT) depended on the length of the material. Short MWCNT were more toxic than the long ones. Studies with human embryo kidney cells (HEK293) revealed that CNT are able to inhibit cell proliferation and to decrease cell adhesion in a dose dependent manner [18]. Wick et al. [19] reported that not only the size, shape, physical and chemical properties, but also the degree of agglomeration of SWCNT alters its effect on cell behaviour of mesothelioma cells in vitro. Well dispersed SWCNT were less cytotoxic than micrometersized agglomerates of SWCNT.

The effects on cell behaviour can be described by a variety of parameters. In case of SWCNT one of the fastest reactions evoked by SWCNT in cell cultures was an oxidative stress [20]. A quantitative analysis of cell adhesion is necessary to understand cell-material surface interaction. Cell adhesion is an interaction between cytoskeleton proteins and focal adhesion proteins and the substratum. The quantity, size and kind of the focal adhesion protein complexes have been described to be correlated with other cell parameters such as cell proliferation, cell activity, cell spreading and cytoskeleton organization [21]. Thus measurement of cell adhesion of cell cultures grown in presence or absence of SWCNT will provide additional information about cell physiology.

The aim of the present study was to compare the effects of purified and non-purified SWCNT (termed SWCNT bundles and SWCNT raw material or SWCNT rm) on cell behaviour of human lung pleural mesothelioma cells (MSTO-211H) and epithelial cells (A549) in order to elucidate SWCNT toxicity. As indices for the effect cell proliferation, cell activity, cytoskeleton organization, apoptosis and cell adhesion were taken as parameters.

\section{Materials and methods}

\subsection{CNT materials}

The investigated SWCNT raw material (SWCNT rm) was purchased from Yangtse Nanotechnology, Shanghai,
China. SWCNT rm was produced by the conventional arcdischarged evaporation of graphite rode filled with nickel and yttrium powder as catalysts. The obtained material was mechanically homogenized by dry mixing using a Braun mixer (maximum power $500 \mathrm{~W}$ ) operating at the lowest speed until a fine powder (no visible grains) was obtained $(5 \times 1 \mathrm{~min}$.). Before use the raw material was sterilized for $3 \mathrm{~h}$ at $160{ }^{\circ} \mathrm{C}$ and dispersed in an aqueous solution containing $40 \mu \mathrm{g} / \mathrm{mL}$ Polysorbate 80 to a final stock solution of $250 \mu \mathrm{g} / \mathrm{mL}$. The latter methodology enables a homogeneous dispersion of CNT. The SWCNT dispersion was subsequently sonicated for $15 \mathrm{~min}$. in an ultra sound bath (Bandelin Sonorex Super RK $156 \mathrm{BH}$ ) and centrifuged for $5 \mathrm{~min}$ at 2,500g for optimal wetting. Then the material was sonicated again as described.

To purify and to separate the SWCNT bundles from the mainly non tubes carboneous fraction (carbon nanotubespellet) the solution was centrifuged for $10 \mathrm{~min}$ at $10,000 \mathrm{~g}$ using an Eppendorf mini spin centrifuge. The concentration of the SWCNT was gravimetrically measured. Polysorbate 80 at the applied concentration had no significant negative effects on cell proliferation and cell activity [19].

Near infrared spectroscopy (NIR) was performed to assess the relative purity of the different SWCNT fractions (SWCNT rm, SWCNT bundles) according to Itkis et al. [22]. The amount of metallic impurities was analyzed by inductive coupled plasma optical emission spectrometry (ICP OES). The amount of $\mathrm{Fe}, \mathrm{Co}, \mathrm{Ca}$ and $\mathrm{Mg}$ in the SWCNT rm was under the detection limit $(\mathrm{Fe}<130 \mu \mathrm{g} / \mathrm{g}$; $\mathrm{Co}<40 \mu \mathrm{g} / \mathrm{g} ; \mathrm{Ca}<340 \mu \mathrm{g} / \mathrm{g} ; \mathrm{Mg}<40 \mu \mathrm{g} / \mathrm{g}$ ). For SEM investigation, a few droplets of a suspension of the SWCNT material were deposited on a support ( $\mathrm{Si}$ wafer). SEM imaging was performed on a LEO 1530 Gemini microscope, which was operated at low voltage $(1 \mathrm{kV})$ to achieve a suitable contrast of the structural details in the secondary electron images and to minimize charging of the uncoated samples. For transmission electron microscopy (TEM), the material was dispersed in ethanol and deposited onto a perforated carbon foil supported on a copper grid. The investigations were performed on a CM30 ST microscope (FEI (Eindhoven); LaB6 cathode, operated at $300 \mathrm{kV}$, resolution ca. $2 \AA$ ). TEM images were recorded with a slow-scan CCD camera. Full SWCNT characterization had been reported in detail by Wick et al. [19].

\subsection{Cell culture}

Human lung mesothelioma cells (cell line, MSTO-211H), American Type Culture Collection (ATCC), Manassas, USA and human lung epithelial cells (A549), European Collection of Cell Cultures (ECACC), Salisbury, UK were used for the present study. They were cultured in 
RPMI-1640 medium (Sigma, Buchs, CH), containing 10\% heat inactivated foetal calf serum (Life Technologies, Basel, $\mathrm{CH}$ ), $1 \%$ PSN-solution (Life Technologies, Basel, $\mathrm{CH}$ ) and $1 \%$ glutamine solution (Life Technologies, Basel, $\mathrm{CH}$ ) under cell culture conditions $\left(5 \% \mathrm{CO}_{2}, 95 \%\right.$ air and $\left.37{ }^{\circ} \mathrm{C}\right)$. Cultures were treated with different concentrations of SWCNT $\mathrm{rm}$ and SWCNT bundles 1 day after plating. After 5 or 6 days of exposure cell functionality was assessed.

\subsection{Cell functionality measurements}

Cell proliferation was estimated by measuring the total culture DNA content. DNA was quantified using the Hoechst 33258 assay. Cell activity was assessed by measuring MTT conversion activity (3-(4,5-dimethylthiazol2-yl)-2,5-diphenyltetrazolium bromide) to its formazan form. Binding of MTT-formazan to SWCNT material was found to be negligible and not to influence the results under the current assay conditions [23].

Cell shape and spreading (cytoskeleton organization) was analyzed by staining of the cell components i.e., actin, vinculin and nuclei using fluorescent dyes. For this cells were fixed using a PBS solution containing $4 \%$ paraformaldehyde and $0.2 \%$ TritonX-100 for $10 \mathrm{~min}$. The actin filaments were stained with BODIPY FL phallacidin in PBS (Molecular Probes, Eugene, USA). Vinculin, which plays a central role in the focal adhesion complexes, was stained by using a first antibody hVin- 1 monoclonal antihuman vinculin (mouse IgG1) (Sigma, Buchs, $\mathrm{CH}$ ) in PBS solution and a second antibody Alexa Fluor 546 labelled goat anti mouse (IgG) in PBS (Molecular Probes, Eugene, USA). Nuclei were stained with a DNA marker (BOBO-1) (Molecular Probes, Eugene, USA). Cultures were thereafter light microscopically analyzed.

Apoptosis/necrosis was estimated qualitatively by using an immunohistochemical detection method (TUNEL: terminal deoxynucleotidyl transferase nick end labelling). The method is based on labelling of DNA strand breaks with fluorescein. In brief, the samples were fixed using a paraformaldehyde solution (4\%), blocked with hydrogen peroxide $(3 \%)$ in methanol and permeabilised with TritonX-100 $(0.1 \%)$. The labelling of the DNA strand breaks was performed by using a labelling solution, which consisted of fluorescein conjugated nucleic acids and a polymerase. The samples were thereafter analysed with a Nikon Eclipse E600FN microscope. The same positions were photographed in the bright field and fluorescent mode.

Cell adherence can be estimated by different methods such as pulling cells from the surface, applying a lateral force with a cantilever or estimating the centrifugal force necessary to detach the cell from the substrate. In this study the influence of SWCNT on cell adhesion was estimated by comparing the centrifugal forces necessary to detach the control cells, which had not been exposed to SWCNT with the forces necessary to detach cells, which had been exposed to SWCNT bundles and SWCNT rm $(30 \mu \mathrm{g} / \mathrm{mL})$ for 5 days.

All experiments were repeated independently three times. Significant effects (cell proliferation, cell activity, cell adhesion) were determined using the ANOVA two factorial Bonferroni/Dunn test with experiment number and SWCNT purity as factors. Differences were considered at $p<0.01$.

\section{Results and discussion}

SWCNT in two different forms, as dispersed SWCNT rm and as SWCNT bundles, were evaluated regarding their physical properties and cytotoxic effects on epithelial cells and mesothelioma cells. The effects on cell functionality were measured by a battery of different parameters. The effects were the following:

\subsection{Proliferation and cell activity}

SWCNT rm as well as SWCNT bundles significantly decreased cell proliferation and cell activity in a dose dependent manner. SWCNT diminished cell proliferation rate and cell activity. Among the two tested cell types the mesothelioma cells reacted most severe on SWCNT treatment (SWCNT bundles as well as SWCNT rm). SWCNT bundles affected cell proliferation and cell activity in a higher manner than the same concentration of SWCNT rm did (Fig. 1a, b). It had been reported that mesothelioma cells were incorporating asbestos nanomaterials very rapidly, compared with other cell types [24]. The fast uptake of carbon nanotubes by mesothelioma cells might be one of the reasons that cell proliferation and cell activity were strongly affected by SWCNT.

\subsection{Cell spreading}

Cell behaviour such as proliferation, cell activity, cell spreading, cytoskeleton architecture and cell adhesion are correlated [21]. The number of focal adhesion is proportional to cell spreading [25]. Cell spreading and cell morphology have been correlated with changes in cell survival, cell proliferation and cellular differentiation [26]. Therefore influence on cytoskeleton organization of SWCNT (SWCNT raw material and SWCNT bundles) in two different concentrations on mesothelioma cells and on epithelial cells have been investigated. 

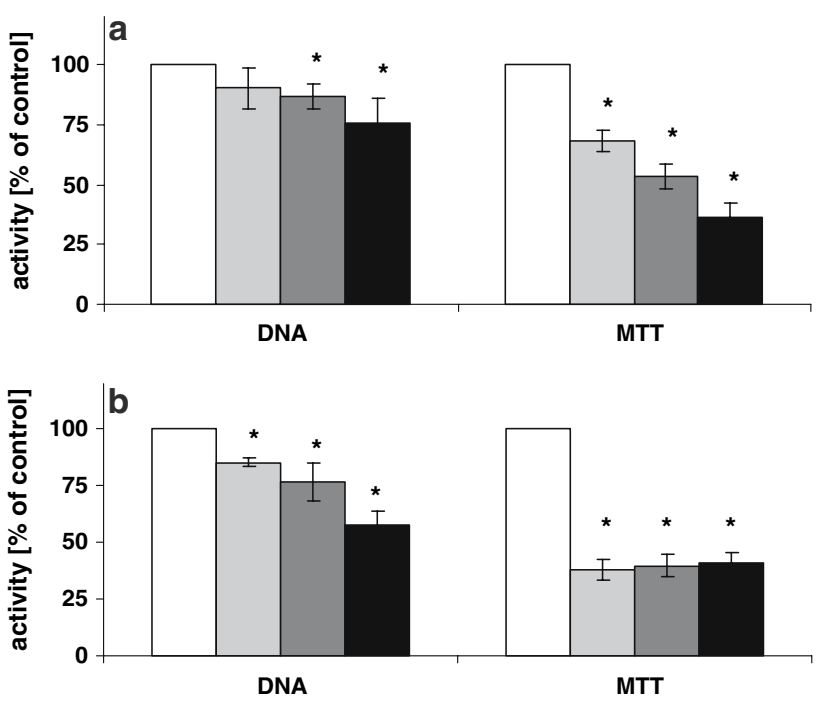

Fig. 1 Effects of SWCNT rm (a) and SWCNT bundles (b) on cell proliferation (DNA) and cell activity (MTT conversion) of mesothe lioma cells after 6 days exposure. White bar control culture, $0 \mu \mathrm{g} / \mathrm{mL}$; grey bar $3.75 \mu \mathrm{g} / \mathrm{mL}$; dark grey bar $7.5 \mu \mathrm{g} / \mathrm{mL}$; black bar $15 \mu \mathrm{g} / \mathrm{mL}$. $*$ = significant different to the control culture $p<0.01$

No remarkable change in the actin cytoskeleton organization of the epithelial cells (A549) in presence $30 \mu \mathrm{g} /$ $\mathrm{mL}$ SWCNT bundles was observed after 5 days exposure to SWCNT particles. SWCNT rm $(30 \mu \mathrm{g} / \mathrm{mL})$ exposed epithelial cells showed after 5 days of exposure still a well established actin cytoskeleton. However, the actin filaments were present as strong bundles at the cell periphery (Fig. 2a).

Control mesothelioma cells (MSTO-211H) developed after 5 days in culture an elongated shape and the actin cytoskeleton was not well spread. SWCNT rm had severe effects on the cytoskeleton organization of the latter cells.
After exposing these cells for 5 days exposure to $15 \mu \mathrm{g} / \mathrm{mL}$ SWCNT rm the cells exhibited an elongated shape with poorly established actin cytoskeleton. In presence of $30 \mu \mathrm{g} /$ $\mathrm{mL}$ SWCNT $\mathrm{rm}$ the actin cytoskeleton of the mesothelioma cells was poorly established and reduced to a very small area around the nucleus (Fig. 2b). Since SWCNT rm contained a higher amount of carboneous material than the SWCNT bundle fraction, it is most likely that the carboneous material in the SWCNT rm solution is responsible for the increased cytotoxic effect.

\subsection{Apoptosis}

Exposure of epithelial and mesothelioma cells to SWCNT bundles $(30 \mu \mathrm{g} / \mathrm{mL})$ for 5 days had no notable effect on programmed cell death as suggested by our TUNEL test results. The epithelial cells were also not affected by SWCNT $\mathrm{rm}$. In contrast, mesothelioma cells formed cell agglomerates under the influence of SWCNT rm $(30 \mu \mathrm{g} / \mathrm{mL})$. The latter cells showed an increased apoptotis/necrosis compared to control cells as suggested by our TUNEL test results. The TUNEL-technology is a tool to estimate apoptosis/necrosis after cells had lost membrane integrity and DNA cleavage had occurred.

\subsection{Cell adhesion}

The cell adhesion force is defined by cell external factors, such as the substratum and medium composition, and cell internal factors, i.e., the functional state of the cell. Adhesion of cells is an energy dependent process. Above we stated that SWCNT affects the cell energy state. In line
Fig. 2 Spreading behaviour (cytoskeleton organization) of endothelial cells (A549) (a, b, c) and mesothelioma cells (MSTO $211 \mathrm{H})(\mathbf{d}, \mathbf{e}, \mathbf{f})$ exposed to SWCNT bundles or SWCNT $\mathrm{rm})$ for 5 days at a concentration of $30 \mu \mathrm{g} / \mathrm{mL}$. (a, d) Control cultures cultivated in absence of SWCNT; (b, e) Cultures cultivated in presence of SWCNT bundles; (c, f) Cultures cultivated in presence of SWCNT rm. Staining: Actin filaments (green), vinculin (yellow) and nucleus (blue)
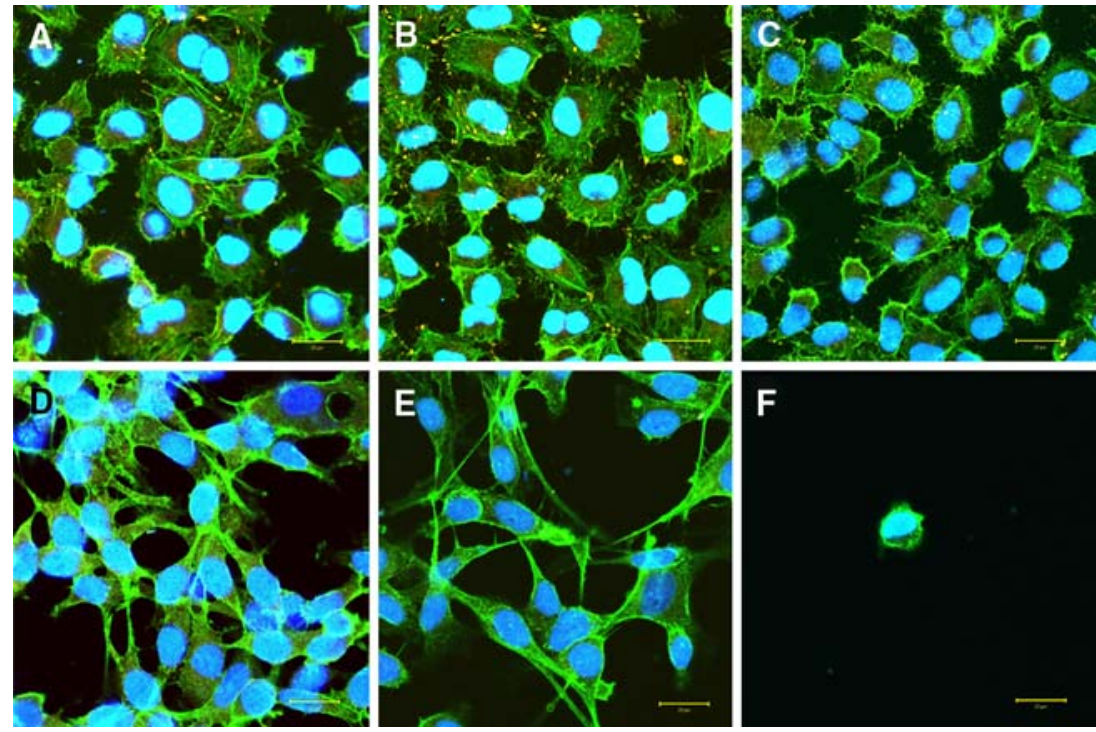
with these and previously reported findings on cell energy state $[19,20]$ we noticed that cells, which were incubated in presence of SWCNT for 5 days exhibited a weaker adherence than the control cells. The effect of SWCNT on cell adherence was dependent on the degree of SWCNT purity (SWCNT bundles or SWCNT rm). SWCNT rm was more toxic and lead to a pronounced decrease in cell adherence than SWCNT bundles did. Higher SWCNT concentration further decreased cell adherence. One of the reasons might be that the transmembrane proteins (integrins) were interacting with the SWCNT and were therefore not able anymore to bind to the substratum. This hypothesis is supported by the observation that cells were less spread, when grown in presence of SWCNT. Another explanation for the reduced cell adhesion is the modification of the total cell functionality. As already discussed by Nobes and Hall [21] cell functionality, defined by characteristics such as cell proliferation rate, cell activity, spreading, cytoskeleton organization and cell adhesion were correlated. Thus, SWCNT were able to influence cell functionality in a time and dose dependent manner.

The above mentioned results clearly show that the purity of SWCNT alters its toxicity and that the effects on cells not only depend on the parameter measured but also on the investigated cell type. Beside physical and chemical parameters of the materials, such as surface chemistry and surface area, also impurities such as catalytic metals as well as amorphous carbon, which are depending from the production method and the manufacturer, were able to influence cell physiology. With the exception for cell proliferation and cell activity all parameters were affected most by the non-purified SWCNT sample (SWCNT rm). Only cell proliferation and cell activity were affected in a higher manner by the purified SWCNT bundles than by the same concentration of non-purified SWCNT rm. The fact that mesothelioma cells are more sensitive to the SWCNT samples indicate that conclusions regarding toxicity may be strongly connected and possibly limited to the cell type used.

Acknowledgements This work has been supported by the European Commission through the integrated project CANAPE (Contract No. NMP4 CT 2004 500096), the Federal Office for Professional Edu cation and Technology Innovation Promotion Agency (OPET CTI), the Swiss Agency for the Environment (BAFU) and the Swiss Federal Office of Public Health (BAG).

\section{References}

1. S. IIJIMA, Nature 354 (1991) 56

2. T. GUO, P. NIKOLAEV, A. THESS, D. T. COLBERT and R. E. Smalley, Chem. Phys. Lett. 243 (1995) 49

3. A. M. CASSELL, J. A. RAYMAKERS, J. KONG and H. DAI, $J$. Phys. Chem. B 103 (1999) 6484

4. A. G. RINZLER, J. LIU, H. DAI, P. NIKOLAEV, C. B. HUFFMAN, F. J. RODRIGUEZ MACIAS, P. J. BOUL, A. H. LU, D. HEYMANN, D. T. COLBERT, J. E. LEE, A. M. RAO, P. C. EKLUND and R. E. SMALLEY, Appl. Phys. A 67 (1998) 29

5. H. MIYAGAWA, M. MISRA and A. K. MOHANTY, J. Nanosci. Nanotechnol. 5 (2005) 1593

6. N. DE JONGE and J. M. BONARD, Philos. Transact. Ser. A. Math. Phys. Eng. Sci. 362 (2004) 2239

7. A. BIANCO, K. KOSTARELOS and M. PRATO, Curr. Opin. Chem. Biol. 9 (2005) 674

8. G. JIA, H. WANG, L. YAN, X. WANG, R. PEI, T. YAN, et al., Environ. Sci. Technol. 39 (2005) 1378

9. J. MULLER, F. HUAUX, N. MOREAU, P. MISSON, J. F. HEILIER, M. DELOS, et al., Toxicol. Appl. Pharmaco. 207 (2005) 221

10. C. M. SAYES, F. LIANG, J. L. HUDSON, J. MENDEZ, W. GUO, J.M. BEACH, et al, Toxicol. Lett. 161 (2006) 135

11. A. HELLAND, P. WICK, A. KOEHLER, K. SCHMID, C. SOM, Environ. Health Persp. (2007) doi:10.1289/ehp.9652

12. C. W. LAM, J. T. JAMES, R. MCCLUSKEY, S. AREPALLI and R. L. HUNTER, Crit. Rev. Toxicol. 36 (2006) 189

13. J. M. WORLE KNIRSCH, K. PULSKAMP and H. F. KRUG, Nano Lett. 6 (2006) 1261

14. F. TIAN, D. CUI, H. SCHWARZ, G. G. ESTRADA and H. KOBAYASHI, Toxicol. in Vitro 20 (2006) 1202

15. A. HUCZKO and A. LANGE, Fullerene Sci. Tech. 9 (2001) 247

16. C. W. LAM, J. T. JAMES, R. MCCLUSKEY and R. L. HUN TER, Toxicol. Sci. 77 (2004) 126

17. J. MULlER, F. HUAUX, N. MOREAU, P. MISSON, J. F. HEILIER and M. DELOS, Toxicol. Appl. Pharm. 207 (2005) 221

18. D. CUI, F. TIAN, C. S. OZKAN, M. WANG, H. GAO, Toxicol. Lett. 155 (2005) 73

19. P. WICK, P. MANSER, L. K. LIMBACH, U. DETTLAFF WEGLIKOWSKA, F. KRUMREICH, S. ROTH, W. J. STARK and A. BRUININK, Toxicol. Lett. 168, 121 (2007)

20. P. WICK, P. MANSER, P. SPOHN and A. BRUININK, Physica. Status. Solidi. 243 (2006) 3556

21. C. D. NOBES and A. J. HALL, J. Cell. Biol. 144 (1999) 1235

22. M. E. ITKIS, D. E. PEREA, S. NIYOGI, S. M. RICKARD, M. A. HAMON, H. HU, B. ZHAO and R. C. HADDON, Nano Lett. 3 (2003) 309

23. A. BRUININK, E. WINTERMANTEL, Biomat. 22 (2001) 2465

24. T. TAKEUCHI, M. NAKAJIMA and K. MORIMOTO, Mutat. Res. 438 (1999) 63

25. C. S. CHEN, M. MRKSICH, S. HUANG, G. M. WHITESSIDES and D. E. INGBER, Science 276 (1997) 1425

26. A. BERSHADSKY, A. CHAUSOVSKY, E. BECKER, A. LY UBIMOVA and B. GEIGER, Curr. Biol. 6 (1996) 1279 